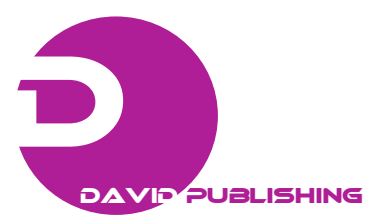

\title{
Innovative Control Strategy for Islanded Small Hydro Power Plant
}

\author{
Roberto Caldon ${ }^{1}$ and Fabio Pasut ${ }^{2}$ \\ 1. Department of Industrial Engineering, University of Padua, Padova 35131, Italy \\ 2. S.T.E. Energy S.p.A., Via Sorio 120, Padova 35141, Italy
}

Received: June 28, 2013 / Accepted: July 31, 2013 / Published: January 31, 2014.

\begin{abstract}
In many developing countries, there are regions where the electrical grid is weak or nonexistent. However, in these areas, large amounts of distributed energy sources, such as hydro, are often available and could be suitably exploited. To this aim, the low head hydro power plants can play a significant role. In fact, recent technological advances in mini-hydro turbines and decreasing costs of static electricity conversion devices enable to realize suitable power plants for an efficient and profitable exploitation of these sites. One of the major challenges is the integration of the above-mentioned power plants into autonomous electrical systems, islanded and/or disconnectable from the main distribution network. In this paper, an innovative control strategy for a low head hydro power plant supplying users in small clusters of villages is proposed.
\end{abstract}

Key words: Islanded systems, micro-grids, permanent magnet synchronous generators, direct torque control.

\section{Introduction}

Projects and technologies for the exploitation of high and medium water heads have been extensively developed in the past, whereas low head sites have been ignored because of the lack of profitability due to the comparatively high civil engineering costs. However, low head hydro represents a renewable energy source with a high potential.

Different types of turbines, such as the VLH (very low head) hydro turbine, nowadays are specifically designed for an efficient and gainful exploitation of the aforesaid sites. This has been made possible by simplifying the civil constructions and adopting standardized turbines with a plain design.

Traditionally, the hydraulic turbines are optimized for a working point defined by speed, head and flow. In order to keep the generation system synchronized with

Corresponding author: Roberto Caldon, professor, research fields: energy economics, dynamics and voltage regulation of large network, power quality in distribution systems, distributed generation and its impact on distribution system. E-mail: roberto.caldon@unipd.it. the main electrical network, the turbine must work at fixed speed. When the working point changes, for example, due to seasonal water head changes, the efficiency appreciably decreases. Power electronics evolution has opened the way to a new variable speed control approach. A power frequency converter decouples the grid frequency from the generator frequency, allowing different generator operation speeds. When the water head changes a new speed set-point is selected to keep the turbine working around the maximum efficiency points.

The concept of islanded operation has today a prominent position [1]. The formation of autonomous self-supplied areas after failures, interruptions or malfunctioning of the main distribution network, could improve the network reliability $[2,3]$. In the developed countries, to allow the islanded operation, the distribution networks would have to be provided with sophisticated control and displacement systems. However, the islanded operation becomes really interesting and helpful where the main electrical grid is 
weak or does not exist. In the developing countries, there are many regions where these conditions are verified.

This paper proposes an innovative control strategy for a low head hydro power plant connected to a micro-grid through a frequency converter and operating in islanded systems.

The possibility of adjusting the PMSG (permanent magnet synchronous generators) generated power through an easy control of the turbine speed has been demonstrated by using a system model and carrying out simulations of step change of load. In particular, the stress due to the load step insertions/rejections has been exasperated beyond realistic levels in order to test the converter behavior (interface generator-load). The focus on the machine-side controller and especially on the active power has led, while aware of the effects of composite loads [4], to simplify the simulations considering only resistive loads. This however, would be the basis for further studies of more complex scenarios.

\section{System Description and Modeling}

The considered power system is composed, as reported in Fig. 1, by:

- a VLH hydro Kaplan turbine;

- a permanent magnet synchronous generator;

- power frequency converter interfacing the generation unit with the micro-grid;

- a low voltage islanded grid.

\subsection{Model of the Hydraulic System and Turbine Inlet}

In the study, a novel type of very low head hydro turbine has been considered in the power plant model. Differently from classic low head turbines, such as vertical Kaplan and bulbs units, the VLH turbine allows a cost-effective exploitation of very low head sites, even less than $3 \mathrm{~m}$.

In recent types of VLH hydro turbines, the generator and the distributor form a simple unique self-supporting structure, placed obliquely in the diversion canal (Fig. 2). The bulb contains the Kaplan

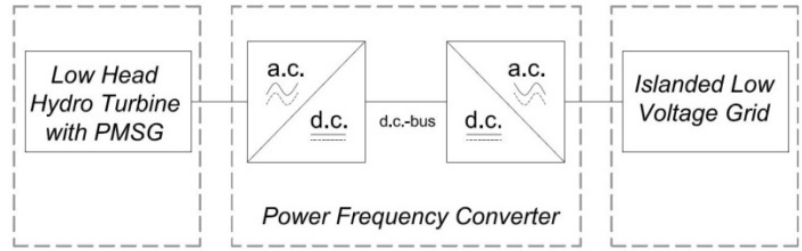

Fig. 1 Schematic diagram of the case study system.

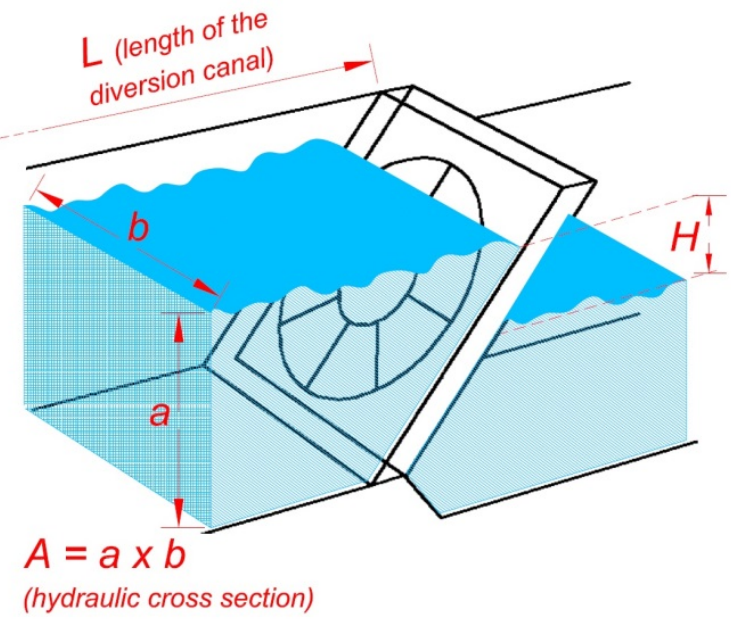

Fig. 2 Positioning of the VLH turbine in the diversion canal.

runner and the PMSG. In particular, the generator stator is placed in a central position in solidarity with the support of the impeller and the rotor magnets are housed inside the Kaplan runner. The generating unit is fully submersible, allowing a silent operation and a low-visual impact [5-7].

A non-linear model of the system, composed by the turbine and the diversion canal, has been considered $[8$, 9]. The basic equation of water flow variation (assuming water as an uncompressible fluid) is:

$$
\frac{d Q}{d t}=-\frac{g A}{L}\left(H-H_{0}\right)
$$

The quantity $(g A / L)$ (which also coincides with the inverse of the water starting time of the turbine supply system, when the variables $Q$ and $H$ are expressed in p.u.) presents negligible variations during the times of the considered transients, therefore, it is assumed in the model for a constant value.

The mechanical torque at the turbine shaft is given by:

$$
T=\frac{\rho g Q H \eta}{\omega}
$$

Water flow and efficiency are function of water head, 
turbine speed and blades pitch-angle. In the normal operation of the turbine (grid-connected mode), the blades pitch-angle control is mainly aimed at maintaining a constant water level in the channel (necessary condition to assure the maximum turbine efficiency even when the water head changes). However, for the aim of this work, a constant value of the blades pitch-angle has been assumed. So the above quantities can be expressed as follows:

$$
\begin{aligned}
& Q=Q(H, \omega) \\
& \eta=\eta(H, \omega)
\end{aligned}
$$

The proposed model of the turbine has been developed on the basis of Eqs. (1) and (2). In particular, by using the turbine performance curves and considering respectively, water head as a function of turbine speed and water flow:

$$
H=f(\omega, Q)
$$

efficiency as a function of turbine speed and water head:

$$
\eta=f(\omega, H)
$$

it is possible to develop a turbine model that requires as dynamic input solely the speed $\omega$ (Fig. 3).

The behavior of hydraulic turbines is usually represented by non-linear characteristics. The resulting operation curves, called performance graphs, are generally provided by the turbine manufacturers, these curves relate turbine speed and water flow for given water head and runner diameter. As an example, a performance graph relevant to a turbine with adjustable rotor blades is shown in Fig. 4. For given water head and runner diameter, water flow is expressed as function of turbine speed and blades pitch angle.

When the performance graph is obtained from a prototype with a diameter equal to one meter and for a water head equal to one meter, the behavior of similar turbines (same geometry, different diameter) for any working condition can be easily determined by the following expressions:

$$
Q=Q_{f}\left(\omega_{f}\right) D^{2} \sqrt{H}
$$

$Q_{f}\left(\omega_{f}\right)$ (fictitious water flow used for the turbine characteristic curves determination) is expressible as function of $\omega_{f}$ for a given blades pitch-angle; $\omega_{f}$

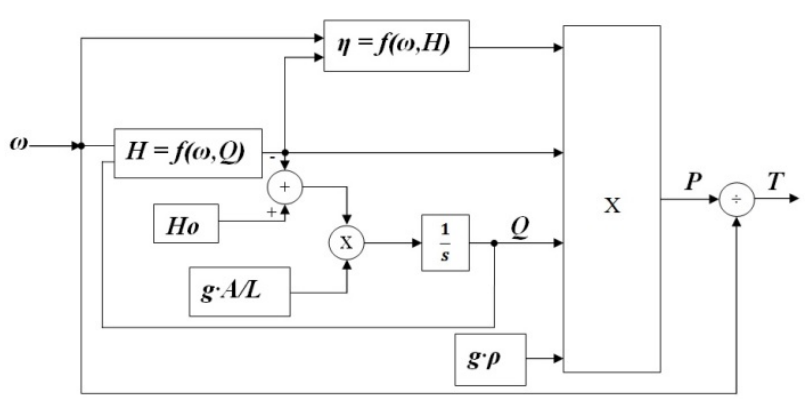

Fig. 3 Turbine model.

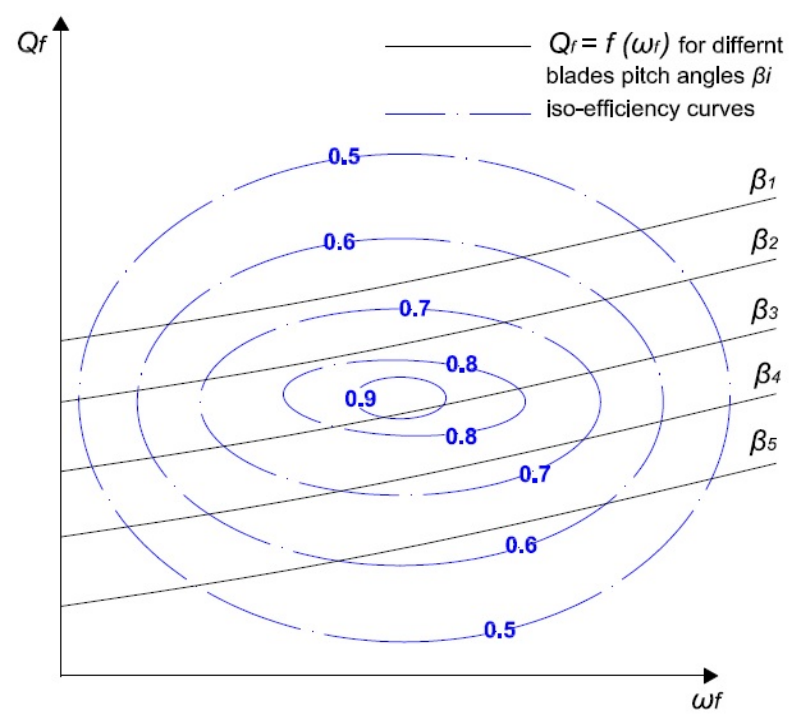

Fig. 4 Kaplan performance graphs.

(fictitious velocity used for the determining the turbine characteristic curves) is given by:

$$
\omega_{f}=\frac{\omega D}{\sqrt{H}}
$$

It can be noted that the determination of $\omega_{f}$ requires knowledge of $\omega$ and $H$, which are model variables.

The procedure used to obtain Eqs. (5) and (6) is detailed in the following. For a fixed value of the blades pitch-angle it is possible to express as:

$$
Q_{f}=a \omega_{f}^{2}+b \omega_{f}+c
$$

Substituting Eq. (8) in Eq. (9) it results:

$$
Q_{f}=a \frac{\omega^{2} D^{2}}{H}+b \frac{\omega D}{\sqrt{H}}+c
$$

By merging Eqs. (10) and (7), the following expression is obtained:

$$
Q \sqrt{H}=a \omega^{2} D^{4}+b \omega D^{3} \sqrt{H}+c D^{2} H
$$

that can be rearranged as:

$$
c D^{2} H+\left(b \omega D^{3}-Q\right) \sqrt{H}+a \omega^{2} D^{4}=0
$$


Making the position $x=\sqrt{H}$ Eq. (12) becomes: $A x^{2}+B x+C=0$ from which $x$, and consequently $H=f(\omega, Q)$, can be obtained.

It is also possible to define, for a given blades pitch-angle, the efficiency $\eta$ as a function of $\omega_{f}$, as:

$$
\eta=a \omega_{f}^{3}+b \omega_{f}^{2}+c \omega_{f}+d
$$

Taking into account Eq. (8), the efficiency may be expressed as a function of $\omega$ and $H$. It is worth noting, as mentioned above, that the only dynamic input for the proposed model is the turbine/generator speed. The initial values of water head $H_{0}$ and water flow $Q_{0}$ must also be known.

\subsection{Modeling the Power Frequency Converter}

Variable and low speeds characterize the VLH turbine operation. This is the reason why the generator is connected to the grid through a power frequency converter [10]. In the paper, a converter having the following features has been considered and modeled: (1) the machine-side converter control is based on the DTC (direct torque control) method; (2) the line-side converter control is based on PWM (pulse width modulation).

DTC has been introduced around the 1990 in permanent magnet motors applications. The operating principle is based on the selection, via the converter command switches, of appropriate voltage vectors in order to control the torque and the stator flux magnitude.

Interesting aspects of the DTC are the reduced complexity and the need to provide a single parameter of the generator; that is the stator winding resistance. Besides, all the calculations in this case can be performed in a stationary reference without knowing the rotor position.

The DTC shows good dynamic behavior but it does not highly perform in steady-state operation; this is due to the voltage vectors selection principle that causes a high ripple in the stator flux, current and electromagnetic torque [11-13].

The DTC method makes it possible to execute a computational cycle in a very short time, so that a high sample frequency can be used; every time the sample frequency doubles, the ripple halves (the sample time is imposed by the switches performances of the converter).

Three signals are involved in the control actions of a DTC system:

- the electromagnetic torque $T e$;

- the stator flux magnitude $|\psi s|$;

- the angle $\delta$ of the resulting flux vector.

Voltage vectors selection (depending on the converter switches status) allows to controlling the flux magnitude acting on speed and direction of stator flux. Stator voltage vector can be expressed as:

$$
v_{s}=\frac{2}{3}\left(v_{a}+v_{b} \mathrm{e}^{j\left(\frac{2}{3}\right) \pi}+v_{c} \mathrm{e}^{j\left(\frac{4}{3}\right) \pi}\right)
$$

where, $v_{a}, v_{b}$ and $v_{c}$ are the actual values of the stator line-neutral voltages. Stator voltages depend directly on converter switches status, $S_{a}, S_{b}$ and $S_{c}$ (Fig. 5).

Therefore, the following vectors can be selected:

\begin{tabular}{l|l|l|l|l|l|l|l|l}
\hline & $V_{1}$ & $V_{2}$ & $V_{3}$ & $V_{4}$ & $V_{5}$ & $V_{6}$ & $V_{7}$ & $V_{8}$ \\
\hline$S_{a}$ & 1 & 1 & 0 & 0 & 0 & 1 & 0 & 1 \\
\hline$S_{b}$ & 0 & 1 & 1 & 1 & 0 & 0 & 0 & 1 \\
\hline$S_{c}$ & 0 & 0 & 0 & 1 & 1 & 1 & 0 & 1 \\
\hline
\end{tabular}

$V_{7}$ and $V_{8}$ are zero voltage vectors [8].

These eight vectors can be written as:

$$
v_{s}\left(\mathrm{~S}_{\mathrm{a}}, \mathrm{S}_{\mathrm{b}}, \mathrm{S}_{\mathrm{c}}\right)=\frac{2}{3} V_{d c}\left(\mathrm{~S}_{\mathrm{a}}+\mathrm{S}_{\mathrm{b}} \mathrm{e}^{\mathrm{j}\left(\frac{2}{3}\right) \pi}+\mathrm{S}_{\mathrm{c}} \mathrm{e}^{\mathrm{j}\left(\frac{4}{3}\right) \pi}\right)
$$

where, $V_{d c}$ is the DC-bus voltage and $2 / 3$ is the Park transformation factor.

PMSG stator flux in a stationary reference is given by:

$$
\psi_{s}=\int\left(v_{s}-R i_{s}\right) \mathrm{d} t
$$

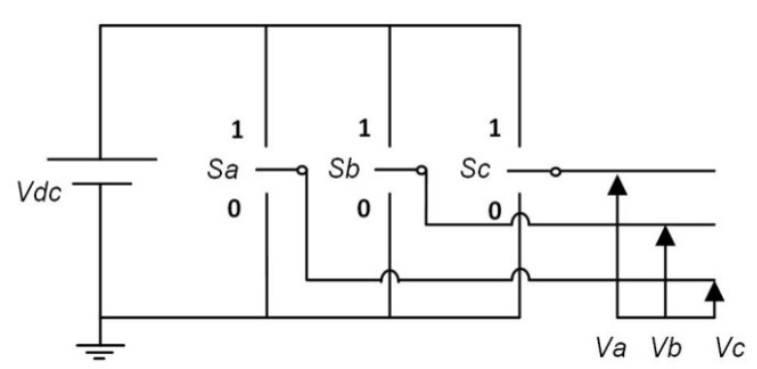

Fig. 5 Machine-side converter switches status. 
where, $R$ is the stator winding resistance and $i_{s}$ is the stator current.

During a commutation period voltage is constant, Eq. (16) may thus be written as:

$$
\psi_{s}=v_{s} t-R \int i_{s} \mathrm{~d} t+\psi_{s} \mid t=0
$$

where, $\left.\psi_{s}\right|_{t=0}$ is the stator flux initial value.

So, stator flux amplitude and electromagnetic torque are controllable performing an appropriate voltage vectors selection. Usually, in the voltage vectors selection, the plane is subdivided in six regions, as shown in Fig. 6. Two contiguous vectors are selected within each region to increase or decrease the stator flux amplitude. The contiguous vectors within each region determine the minimum commutation frequency.

In a PMSG, the stator flux is established by both the stator voltage and the magnets flux. Therefore, as long as the rotor is moving, the stator flux exists even if zero voltage vectors are applied. As a result, the application of zero voltage vectors only produces sudden torque decay. For this reason, zero voltage vectors can not be used. Compared with the rotor flux, $\psi_{s}$ must be always in motion.

As stated above the electromagnetic torque can be adjusted by controlling the magnitude and rotational speed of the stator flux. In anticlockwise operation, if the actual torque is smaller than the reference value, voltage vectors that keep rotating in the same direction are selected. $\delta$ angle value increases and consequently the actual torque increases. When the torque is higher than the maximum reference value, voltage vectors that keep $\psi_{s}$ rotating in the opposite direction are selected, $\delta$ decreases and the torque decreases too.

The PWM logic in the line-side converter is able to control the voltage (in magnitude and frequency) in order to maintain the value within the imposed limits, provided that the voltage value of the DC-bus is held constant. Fig. 7 illustrates the schematic diagram for the power system control. A capacitor is derived from the DC-bus, in order to reduce and smooth the voltage transients. As just said above, the stress due to the load

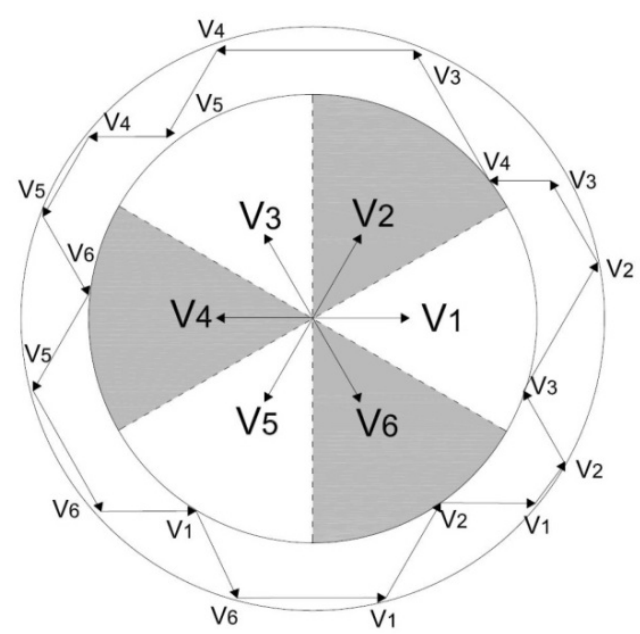

Fig. 6 Plane subdivision and voltage vectors selection strategy to keep the stator flux within the fixed range.

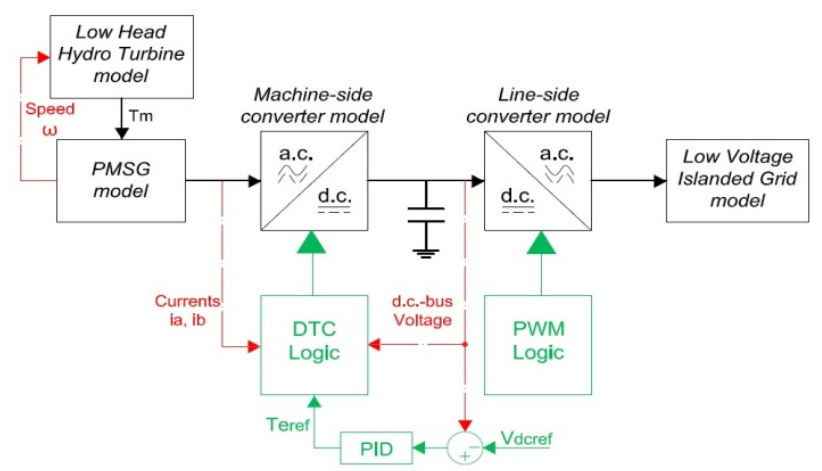

Fig. 7 Scheme of the control for the islanded power system.

step insertions (rejections) have been exasperated beyond realistic levels; in practice, it should adjust the characteristics of the capacitor but the correct sizing of components was not in the purpose of work.

\section{Control Strategy for Islanded Operation}

The proposed control strategy has been developed aiming at feeding a passive islanded low voltage network subject to the following constraints:

- The power system must be "generator based control", namely the generation must follow the requirements of the loads without receiving any communication from the latter or from other generators;

- In islanded mode, the power plant modifications with respect to its common operation mode (grid-connected) should be kept to minimum allowable. Components standardization should not be compromised. 
The basic target for the system is the maintenance of voltage and frequency variations within the required limits [14]. Since line-side converter has been provided with PWM logic, it is inherently capable to control its output voltage amplitude and frequency. However, this is true only if the DC-bus voltage is kept constant. To this aim, the balance between generated power and absorbed power has to be guaranteed.

\subsection{Active Power Management}

Generally, loads are connected to the grid by step insertions. Responsibility of the generator is to respond dynamically to the demand of the load keeping the voltage amplitude and frequency within the limits in every point of the island.

The proposed strategy uses the variable speed operation potentialities. The turbine is considered as a kinetic energy storage device. The energy variation between two equilibrium states is thus:

$$
\Delta E=\frac{1}{2} I\left(\omega_{1}^{2}-\omega_{2}^{2}\right)
$$

With an appropriate converter switches management (DTC method), it is possible to control the electromagnetic torque at motor/generator output. Starting from this assumption, the generator active power has been controlled through an appropriate electromagnetic torque management, letting the turbine increasing or decreasing its speed.

The proposed control strategy is based on the following assumptions:

- The DC-bus voltage is taken as reference;

- When the DC-bus voltage decreases compared with a fixed value, it means that the electromagnetic torque at the generator output is lower than necessary. On the contrary, if the DC-bus voltage increases, it means that the electromagnetic torque at the generator output is higher than necessary.

Therefore, to keep the DC-bus voltage within the limits, the machine-side converter logic has to provide suitable reference electromagnetic torque values; the active power balance between produced and required power is consequently guaranteed.
At a practical level, the control procedure may be implemented using two different ways:

(1) In the software that manages the machine-side inverter. In this case, manufacturers of static converters must be involved;

(2) In a dedicated hardware. This external device must be interfaced with the frequency converter. This one must be able to receive an electromagnetic torque reference value as external input, through a cabled signal from the external controller.

In the machine-side converter the torque reference value has been assumed to vary from $100 \%$ to 0 according to the variation from a min. to a max. set value of the DC-bus voltage with a linear relationship. The actual value of the DC-bus voltage is compared with its reference value; then a proper electromagnetic torque reference value is selected, in order to vary the speed of the turbine so that the power balance is reached (Fig. 7).

The maximum electromagnetic torque obtainable is directly proportional to the maximum mechanical torque available from the turbine which in turn depends on the turbine operating conditions, in particular on the available water head.

With the proposed control strategy, based on the voltage vectors selection, different load torques are applied to the turbine. The turbine increases or decreases its speed depending on the electromagnetic torque reference.

Fig. 8 shows a typical turbine $P-\omega$ characteristic for a given water head (it is worth noting that the speed corresponding to the maximum $P$ depends on the water head under which the turbine is working). In the diagram, the range of operating points involved by the proposed control strategy is identified.

\section{Analysis and Simulation Results}

Analysis have been performed on the system shown in Fig. 1; characteristics assumed in the case study (namely the parameters of the generator and the turbine) are reported in Table 1. 


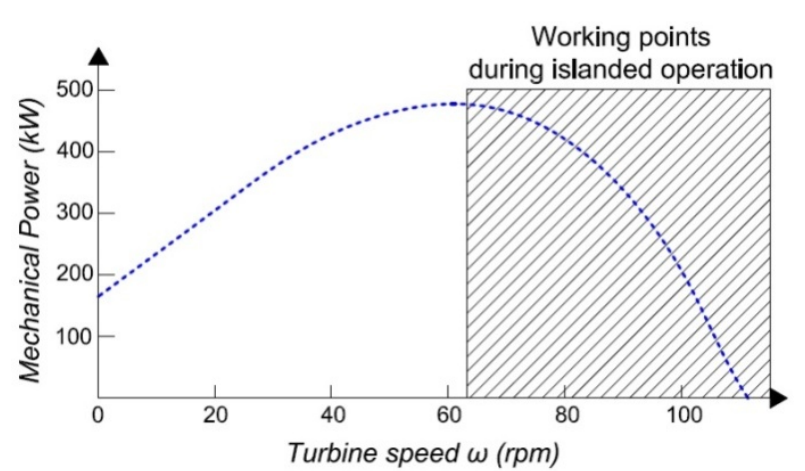

Fig. 8 Turbine $\boldsymbol{P}$ - $\omega$ characteristic; working points during islanded operation.

Table 1 Parameters of the generator and the converter.

\begin{tabular}{lc}
\hline \multicolumn{2}{c}{ PMS generator characteristics } \\
\hline Rated power (kVA) & 500 \\
Rated voltage $(\mathrm{V})$ & 500 \\
Cos $\varphi$ & 0.8 \\
Frequency $(\mathrm{Hz})$ & 32.5 \\
\hline \multicolumn{2}{c}{ Turbine characteristics } \\
\hline Rated mechanical power $(\mathrm{kW})$ & 560 \\
Rated speed (rpm) & 69 \\
$\mathrm{~N}^{\circ}$ blades & 8 \\
Considered blade pitch angle $\left(^{\circ}\right)$ & 17 \\
\hline
\end{tabular}

A tolerance band of $\pm 10 \%$ of the DC-bus voltage reference value has been considered.
Several dynamic simulations concerning different operating conditions for the islanded network have been carried out. In particular, the system behavior for different step load insertions has been investigated. To this aim a power plant model has been implemented in MATLAB/Simulink, Fig. 9 illustrates the block diagram of the model formed by:

- very low head hydro turbine model (presented in Section 2.1);

- permanent magnet synchronous generator model (available in the Simulink library);

- frequency converter model; control logic of the machine-side converter (DTC); control logic of the line-side converter (PWM) (presented in Section 2.2);

- model of the proposed controller integrated in the DTC algorithm (presented in Section 3);

- low voltage grid model (consisting of a transformer, a line and three resistive loads).

Following are the main results of the simulations, in particular, the behavior of the system in face of severe load changes (significant load step of connection and disconnection).

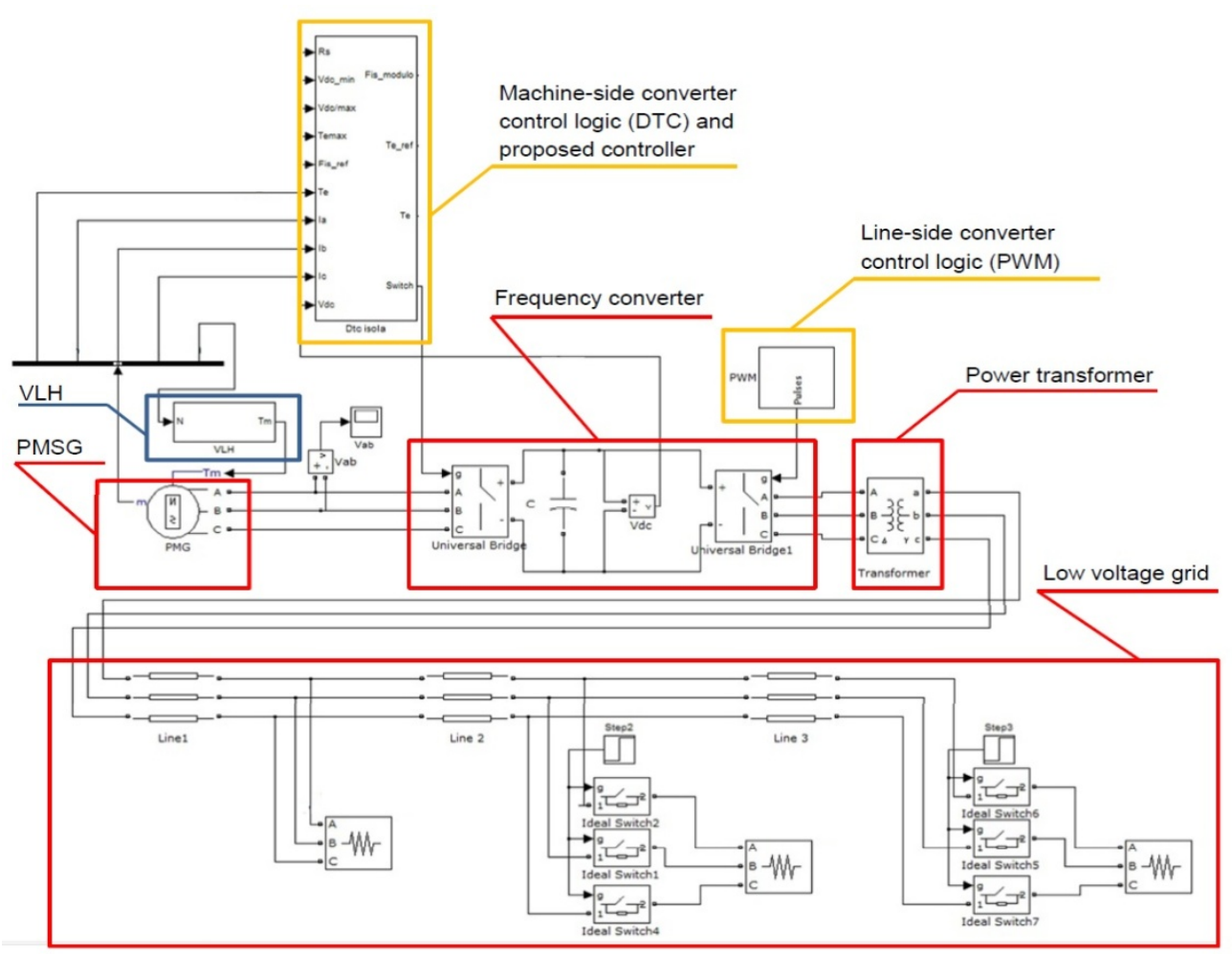

Fig. 9 Block diagram of the simulation model. 
Fig. 10 shows the turbine mechanical power and speed curves, as a result of two consecutive load step changes. The power value of each load change is $25 \%$ of the generator rated power.

As already explained, the turbine acts as a kinetic energy storage device; when a power increase is required, the turbine reduces its speed in order to provide the requirement. On the contrary, when a load rejection occurs, the turbine is accelerated by the different relationship of torques.

Fig. 11 shows, for the above conditions (considered in Fig. 10), the DC-bus voltage and the supply voltage of loads during the dynamic behavior of power balance, it can be noted only a weak variation within $10 \%$. With the proposed control strategy, the VLH hydro turbine is able to maintain voltage around the reference value.

Then, in the search of acceptable operating conditions limit, a step change of load about $50 \%$ of the generator rated power has been simulated. Fig. 12 shows the turbine mechanical power and speed curves, as a result of one load step insertion and one load step rejection.

Fig. 13 shows the relevant DC-bus voltage during the dynamic behavior of power balance. Even in this case, the period in which the voltage remains over the limits is low, but the maximum voltage peak may be unacceptable.

An interesting synthesis of what occurred with the simulations is reported in Table 2. It can be seen that the voltage peak variation values and the time in which they remain outside the $\pm 10 \%$ band are extremely low, even in case of severe load step insertions and rejections.

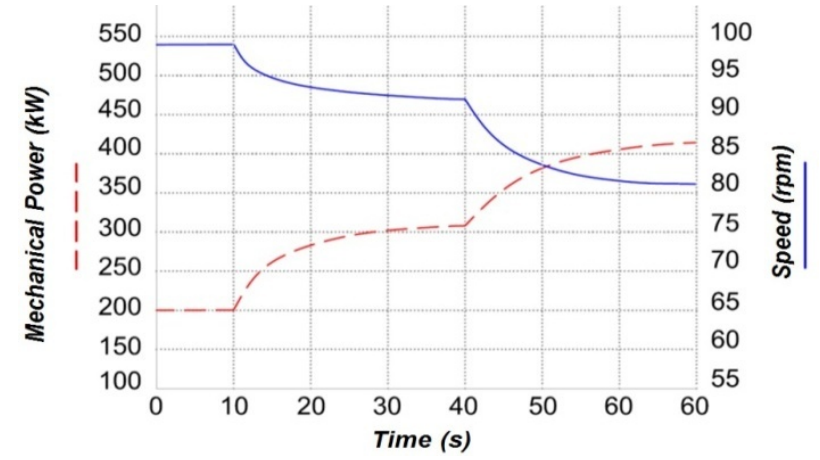

Fig. 10 Generated mechanical power and turbine speed during consecutive load step insertions.
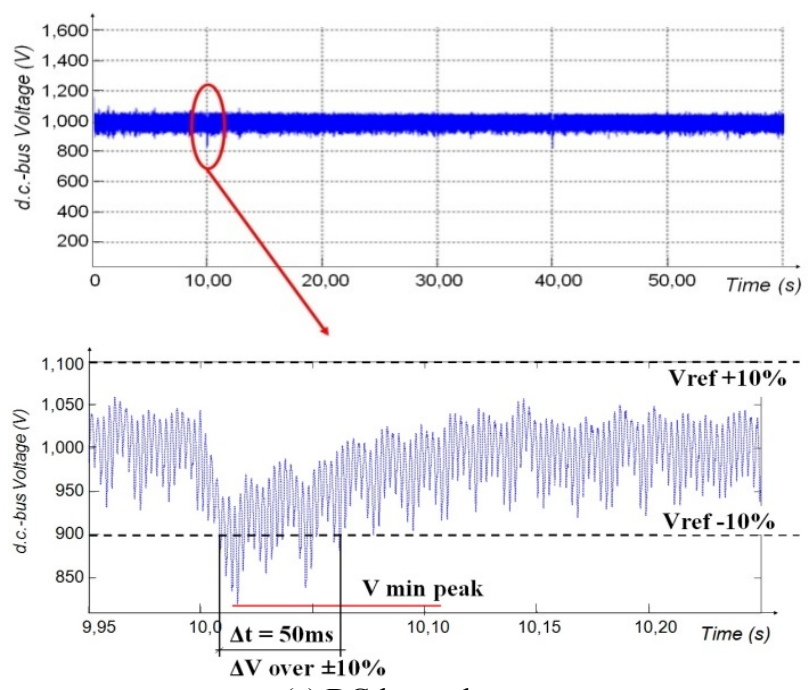

(a) DC-bus voltage

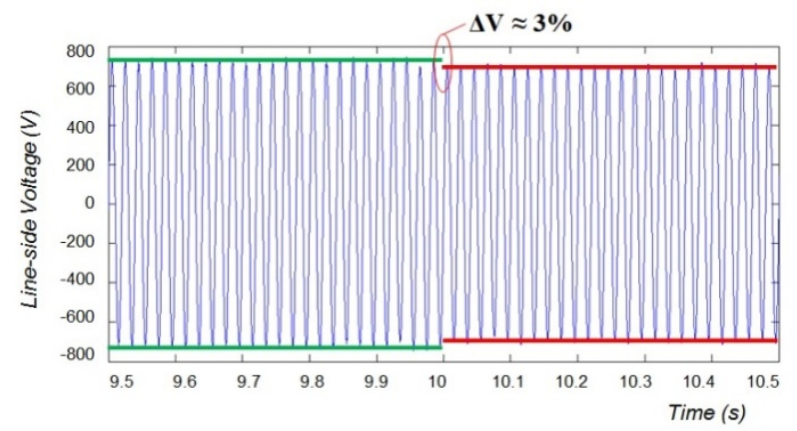

(b) Line-side voltage

Fig. 11 (a) DC-bus voltage and (b) line-side voltage during the consecutive load step insertions.

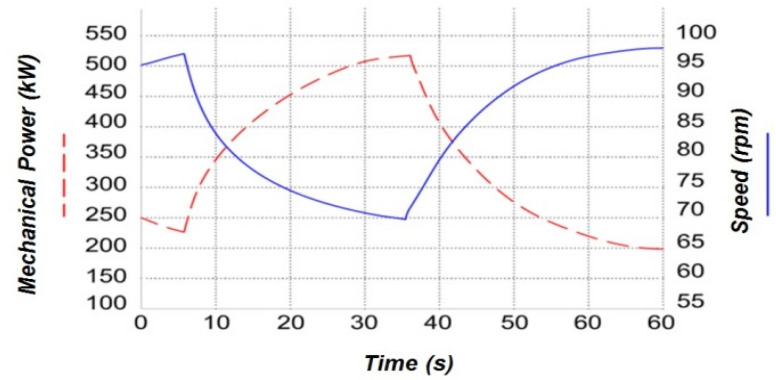

Fig. 12 Generated mechanical power and turbine speed during two severe load step changes (insertion and rejection).

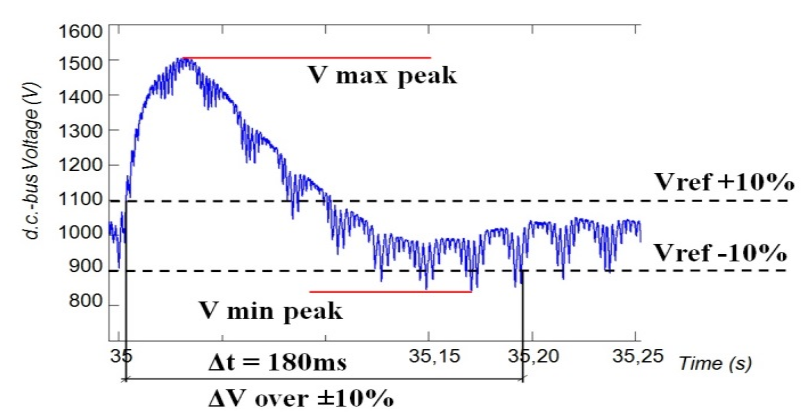

Fig. 13 DC-bus voltage during a severe load step rejection. 
Table 2 DC-bus voltage drop peak values and duration of exceeding the limits $( \pm \mathbf{1 0} \%)$.

\begin{tabular}{|c|c|c|c|}
\hline \multicolumn{2}{|l|}{ Event } & \multirow{2}{*}{$\begin{array}{l}\text { Voltage peak deviation from the set value (p.u.) } \\
-0.18\end{array}$} & \multirow{2}{*}{$\begin{array}{l}\text { Duration of exceeding a bandwidth of } \pm 10 \%(\mathrm{~ms}) \\
50\end{array}$} \\
\hline Medium step load & Insertion & & \\
\hline$\left(0.25 P_{\text {gen. }}\right)$ & Disconnection & +0.18 & 50 \\
\hline $\begin{array}{l}\text { High step load } \\
\left(0.6 P_{\text {gen }}\right)\end{array}$ & $\begin{array}{l}\text { Insertion } \\
\text { Disconnection }\end{array}$ & $\begin{array}{l}-0.3 \\
+0.5\end{array}$ & $\begin{array}{l}140 \\
180\end{array}$ \\
\hline
\end{tabular}

\section{Conclusions}

A novel control strategy for small low head hydro power plant equipped with permanent magnet synchronous generators and operating in islanded conditions has been presented.

The proposed method, that requires only few modifications to the interface converter, has demonstrated the possibility to dynamically balance the power required by the loads in a micro-grid. The simulation results show the ability to cope with load step change up to $30 \%$ of the generating unit rated power (while for variations in excess of this range it has been found that voltage drops/rises in converter DC-bus become unsustainable).

The study has been focused on the machine-side controller with the purpose of verifying the stability of the system for very heavy disturbance. Remain to conduct further studies on the behavior of the line-side converter in the presence of rotating machine loads.

\section{Acknowledgments}

The authors wish to thank S.T.E. Energy S.p.A. for providing data and professional expertise about VLH turbines.

\section{References}

[1] P. Piagi, R.H. Lasseter, Autonomous control of microgrids, in: IEEE PES Meeting, Montreal, Canada, Jun. 2006.

[2] H. Karimi, H. Nikkhajoei, R. Iravani, Control of an electronically coupled distributed resource unit subsequent to an islanding event, IEEE Trans. on Power Delivery 23 (1) (2008) 493-501.

[3] J.A. Peças Lopes, Defining control strategies for microgrids islanded operation, IEEE Trans. on Power Systems 21 (2) (2006) 916-924.

[4] G. Diaz, C. Gonzalez-Moran, J. Gomez-Aleixandre, A. Diez, Composite loads in stand-alone inverter-based microgrids-Modeling procedure and effects on load margin, IEEE Trans. on Power Systems 25 (2) (2010) 894-905.

[5] R. Fraser, C. Deschênes, J.L. Kueny, C. O’Neil, M. Leclerc, VLH: Development of a new turbine for very low head sites, in: Waterpower XV, Chattanooga, TN, USA, Jul. 2007.

[6] P. Lautier, H.J.N. Ndjana, M. Leclerc, C. O’Neil, Improved operation and power production of a very low head hydraulic turbine, in: Waterpower XV, Chattanooga, TN, USA, Jul. 2007, http://www.vlh-turbine.com/DE/PDF/evenements/WaterP ower2007_Philippe_Lautier.pdf.

[7] M. Leclerc, The very low head turbo generator: A new turbine for profitable harnessing of very low head applications, in: Hydro 2007, Granada, Spain, Oct. 2007.

[8] M. Brezovec, I. Kuzle, T. Tomisa, Non-linear digital simulation model of hydroelectric power unit with Kaplan turbine, IEEE Trans. on Energy Conversion 21 (1) (2006) 235-241.

[9] E. De Jaeger, N. Jannsens, B. Malfliet, F. Van De Meulebroeke, Hydro turbine model for system dynamic studies, IEEE Trans. on Power System 9 (4) (1994) 1709-1715.

[10] P. Lautier, C. O’Neil, C. Deschênes, H.J.N. Ndjana, R. Fraser, M. Leclerc, Variable speed operation of a new very low head hydro turbine with low environmental impact, in: Proc. IEEE Canada Electrical Power Conference, EPC 2007, Montreal, Canada, Oct. 2007, pp. 85-90.

[11] Z. Lu, H. Sheng, H.L. Hess, K.M. Buck, The modelling and simulation of a permanent magnet synchronous motor with direct torque control based on Matlab/Simulink, in: IEEE Int. Conf. on Electric Machines and Drives, San Antonio, TX, USA, May 15, 2005, pp. 1150-1156.

[12] B. Lang, W. Liu, X. Zhou, R. Li, Research on direct torque control of permanent magnet synchronous motor based on optimized state selector, in: IEEE ISIE, Montréal, Canada, Jul. 2006, pp. 2105-2109.

[13] L. Zhong, M.F. Rahman, W.Y. Hu, K.W. Lim, Analysis of direct torque control in permanent magnet synchronous motor drives, IEEE Trans. on Power Electronics 12 (3) (1997) 528-536.

[14] H. Zeineldin, E.F. El-Saadany, M.M.A. Salama, Intentional islanding of distributed generation, in: IEEE PES General Meeting, San Francisco, CA, USA, Jun. 2, 2005, pp. 1496-1502. 